\section{OPEN ACCESS}

Edited by:

Alberto Albanese,

Catholic University of the Sacred

Heart, Italy

Reviewed by:

Maria Teresa Pellecchia

University of Salerno, Italy

Giuseppe De Michele,

University of Naples Federico II, Italy

*Correspondence:

Stefano Renzett

stefano.renzetti@unibs.it

Specialty section:

This article was submitted to

Movement Disorders,

a section of the journal

Frontiers in Neurology

Received: 28 April 2020 Accepted: 13 November 2020 Published: 09 December 2020

Citation:

Lucchini RG, Guazzetti S, Renzetti S,

Broberg K, Caci M, Covolo L,

Crippa P, Gelatti U, Hashim D,

Oppini M, Pepe F, Pilotto A, Passeri C

Placidi D, Rizzetti MC, Turla M,

Wahlberg K and Padovani A (2020)

Metal Exposure and SNCA rs356219

Polymorphism Associated With

Parkinson Disease and Parkinsonism.

Front. Neurol. 11:556337.

doi: 10.3389/fneur.2020.556337

\title{
Metal Exposure and SNCA rs356219 Polymorphism Associated With Parkinson Disease and Parkinsonism
}

\begin{abstract}
Roberto G. Lucchini ${ }^{1,2}$, Stefano Guazzetti ${ }^{3}$, Stefano Renzetti ${ }^{2 *}$, Karin Broberg ${ }^{4,5}$, Margherita $\mathrm{Caci}^{2}$, Loredana Covolo ${ }^{2}$, Patrizia Crippa ${ }^{6}$, Umberto Gelatti ${ }^{2}$, Dana Hashim ${ }^{7}$, Manuela Oppini ${ }^{2}$, Fulvio Pepe ${ }^{8}$, Andrea Pilotto ${ }^{9,10}$, Chiara Passeri ${ }^{2}$, Donatella Placidi ${ }^{2}$, Maira Cristina Rizzetti ${ }^{10}$, Marinella Turla ${ }^{11}$, Karin Wahlberg ${ }^{4}$ and Alessandro Padovani ${ }^{9}$
\end{abstract}

${ }^{1}$ Robert Stempel College of Public Health, Florida International University, Miami, FL, United States, ${ }^{2}$ Department of Medical Surgical Specialities, Radiological Sciences and Public Health, University of Brescia, Brescia, Italy, ${ }^{3}$ Azienda USL-IRCCS di Reggio Emilia, Reggio Emilia, Italy, ${ }^{4}$ Division of Occupational and Environmental Medicine, Lund University, Lund, Sweden, ${ }^{5}$ Institute of Environmental Medicine, Karolinska Institutet, Solna, Sweden, ${ }^{6}$ Ancelle Della Carità, Brescia, Italy, ${ }^{7}$ Hematology \& Medical Oncology, Icahn School of Medicine at Mount Sinai, New York, NY, United States, ${ }^{8}$ Neurology, Poliambulanza Foundation, Brescia, Italy, ${ }^{9}$ Neurology Unit, Department of Clinical and Experimental Sciences, University of Brescia, Brescia, Italy, ${ }^{10}$ Parkinson Rehabilitation Center, Ospedale S. Isidoro - FERB Onlus, Trescore Balneario, Bergamo, Italy, ${ }^{11}$ Esine Hospital of Valcamonica, Brescia, Italy

Objective: In the province of Brescia, Italy, historical neurotoxic metal exposure has occurred for several decades. This study aimed to explore the role of metal exposure and genetics on Parkinson's Disease (PD) and Parkinsonism.

Methods: Cases were enrolled from four local clinics for movement disorders. Randomly selected controls non-affected by neurological or psychiatric conditions were enrolled from the same health centers keeping a similar gender ratio and age distribution as for cases. Data on sociodemographic variables, clinical onset and life habits were collected besides accurate occupational and residential history. Blood samples were collected from all participants for genotyping of target polymorphisms in genes linked to PD and/or metal transport.

Results: A total number of 432 cases and 444 controls were enrolled in the study, with average age of 71 years (72.2 for cases and 70 for controls). The average age at diagnosis was 65.9 years (SD 9.9). Among the potential risk factors, family history of PD or Parkinsonism showed the strongest association with the diseases $(\mathrm{OR}=4.2,95 \% \mathrm{Cl} 2.3,7.6$ on $\mathrm{PD} ; \mathrm{OR}=4.3,95 \% \mathrm{Cl} 1.9,9.5$ for Parkinsonism), followed by polymorphism rs356219 in the alpha-synuclein (SNCA) gene (OR $=2.03$, $95 \% \mathrm{Cl} 1.3,3.3$ for $\mathrm{CC}$ vs. TT on PD; OR $=2.5,95 \% \mathrm{Cl} 1.1,5.3$ for $\mathrm{CC}$ vs. TT on Parkinsonism), exposure to metals ( $\mathrm{OR}=2.4 ;, 95 \% \mathrm{Cl} 1.3,4.2$ on $\mathrm{PD}$ ), being born in a farm $(\mathrm{OR}=1.8 ; 95 \% \mathrm{Cl} 1.1,2.8$ on $\mathrm{PD}$; $\mathrm{OR}=2.6$; $95 \% \mathrm{Cl} 1.4,4.9$ on Parkinsonism) and being born in the province of Brescia $(O R=1.7 ; 95 \% \mathrm{Cl}$ 1.0, 2.9 on PD). Conditional OR of having PD depending by SNCA polymorphism and metal exposure highlights higher risk of PD among CC SNCA carriers and being exposed to metals. However, the interaction term was not statistically significant. 
Conclusions: Lifetime exposure to metals and genetic variation in SNCA gene are
relevant determinants of PD and Parkinsonism in the highly industrialized area of Brescia,
Italy. The lack of evidence of statistical interaction between environmental and genetic
factors may be due to the low frequencies of subjects representing the exposure
categories and the polymorphism variants and does not rule out the biological interaction.

Keywords: metal exposure, SNCA gene, parkinsonism, parkinson disease, occupational exposure, manganese

\section{INTRODUCTION}

The province of Brescia, northern Italy, was characterized by an historical metallurgic and ferromanganese industrial activities. A higher prevalence of Parkinsonism has been observed among municipalities closer to ferromanganese plants $(492 / 100,000)$ compared to other province municipalities $(321 / 100,000)$ (1). A significant association between the Bayesian Standardized Morbidity Ratios (SMRs) for Parkinsonism and dust manganese (Mn) concentrations was also found (1). A case-control study in the same area showed higher levels of blood $\mathrm{Mn}$, copper $(\mathrm{Cu})$ and zinc $(\mathrm{Zn})$ among the cases residing around the ferroalloy plants of Valcamonica (2-4). Studies from our group have shown high levels of $\mathrm{Mn}$, arsenic (As), cadmium (Cd), chromium (Cr), Cu, iron $(\mathrm{Fe})$, lead $(\mathrm{Pb})$, nickel (Ni), $\mathrm{Zn}(5-9)$ in environmental media including airborne particles $(5,10-13)$, indoor and outdoor deposited dust (7), attic dust (6), soil $(8,14)$, and locally grown produce (9). This exposure to metals has been associated with biomarkers (15) and neurobehavioral outcomes in children $(16-19)$, workers $(20-22)$, and elderly $(23,24)$ residing in the area, indicating adverse health outcomes of the metal exposure. Further, genetic susceptibility for some of the metal-associated effects have been observed (25-29). Essential metals including $\mathrm{Zn}, \mathrm{Cu}, \mathrm{Mn}$, and Fe play critical roles in the pathophysiology of neurodegenerative diseases including PD (30), also by inducing alpha-synuclein modifications (31-34).

Gene-environment interactions have been identified in association with PD (35), particularly for metal exposures (36). Measuring genetic susceptibility markers in metal exposed populations (37) becomes critical to identify susceptible groups to Parkinsonian disturbances and preventing disease onset and progression. In a case-control study of 874 individuals we aimed to assess whether PD is associated with metal exposure, mainly assessed through job exposure, and examine the associations between PD- and metal-associated single nucleotide polymorphisms (SNPs) and its interaction with metal exposure.

\section{METHODS}

\section{Case Definition and Enrollment}

The case definition was not restricted to the diagnostic criteria of IPD, but extended to the broader classification of Parkinsonism (i.e., Parkinsonism and/or PD). This was defined by the presence of at least two of the cardinal features: (i) bradykinesia/akinesia; (ii) rigidity; (iii) tremor; (iv) postural instability (38), and with the exclusion of cases based on vascular, iatrogenic, and traumatic origin. Four centers followed a common case definition and diagnostic protocol and prevalent cases were recruited and reviewed by a single neurologist from any one of the centers specialized in movement disorders located in the Province of Brescia at the following Institutions: ASST-Spedali Civili of Brescia, Esine Hospital of Valcamonica, Poliambulanza Foundation, Ancelle Domus Salutis. Each patient was evaluated by the neurologists attending in each center: authors AP, MCR, AP at Spedali civili, FP at Poliambulanza Foundation, MT at Esine Hospital, PC at Ancelle Brescia. Diagnosis of PD and atypical parkinsonism was performed according to clinical criteria (39). Non-Parkinsonian/PD controls were recruited from the clinics of Dermatology, Orthopedics, Ophthalmology and Otorhinolaryngology of the same hospitals, in order to provide a similar geographic distribution of the residencies of the cases.

All subjects underwent blood sampling for DNA analyses at enrollment.

\section{Standard Protocol Approvals, Registrations, and Patient Consents}

The study design and consent were approved by the Ethical Committee of the Department of Health, Brescia, and each participant was consented after receiving written and oral explanation about the study aims and methodology. Exclusion criteria were any neurological or psychiatric condition other than parkinsonian disorders.

\section{Questionnaires}

Data on demographics, lifestyle habits, family history of Parkinsonism/PD (if either the mother or the father had Parkinsonism or PD; only parents were considered to decrease the potential recall bias) and, for the cases, clinical diagnosis, age at onset and clinical data were collected through questionnaires. An exposure questionnaire was administered to cases and controls to gain information about their occupational and residential history. Self-reported occupational exposures to specific neurotoxic metals (aluminum, antimony, As, beryllium, $\mathrm{Cd}, \mathrm{Cu}, \mathrm{Cr}$, gallium, magnesium, $\mathrm{Mn}$, mercury, $\mathrm{Ni}, \mathrm{Pb}$ ) were recorded. Because of the low frequencies of the exposure to the single metals, an overall exposure measure was considered in the study identifying those subjects with at least one occupational exposure to metals in their job life (before diagnosis for the cases).

Participants were also asked to report job titles, tasks, industries, starting dates and duration (in years) of each job.

\section{Genotyping}

Polymorphisms known to be associated with Parkinsonism and/or PD and/or with handling (e.g., uptake and transport) 
of metals in the body were measured: (i) solute carrier family 30 member 10 (SLC30A10: rs2275707, rs12064812, rs1776029) (27); (ii) solute carrier family 39 member 8 (SLC39A8/ZIP8: rs13107325) (28); (iii) PARK9-associated cation-transporting ATPase 13A2 (ATP13A2: rs4920608 and rs2871776) (40); (iv) synuclein alpha (SNCA: rs356219) (41); (v) divalent metal transporter 1 (DMT1: IVS4+44G/T, rs224589) (42).

DNA was extracted from $0.2 \mathrm{ml}$ of peripheral whole blood samples using the QIAamp DNA Blood Mini kit (Qiagen, Hilden, Germany). Genotyping was performed with TaqMan real time PCR for rs2275707, rs12064812 and rs13107325 (Thermo Scientific assays), as previously described (26, 27); and for rs4920608, rs2871776, rs224589, and rs356219 (Life Technologies assays). Rs1776029 is situated in the middle of an Alu-repeat region of approximately $300 \mathrm{bp}$ in length, and a satisfactory TaqMan SNP assay with respect to specificity and amplicon length could not be designed for this SNP. Therefore, rs1776029 was instead genotyped by pyrosequencing as previously described (26). Generation of PCR products and pyrosequencing was performed using the PyroMark reagents and PSQ HS96 Pyrosequencing System (Qiagen) according to manufacturer's instructions. For quality control of genotyping data, $>5 \%$ of samples were re-analyzed for all SNPs in a separate round of experiment with a $100 \%$ agreement between duplicate.

\section{Statistical Analyses}

Hardy-Weinberg equilibrium (HWE) analysis was undertaken to determine deviation from genotype frequencies using the conventional $\chi 2$-test. The association of exposure to metals and each SNP with Parkinsonism and PD was assessed using multinomial regression setting controls as the reference category. For metals exposure, categories were defined as "Ever been exposed" vs. "Never exposed to." For SNPs both $\chi 2$-test and multivariate (adjusted for all terms) odds ratios (ORs) were obtained as a measure of association between the genetic polymorphisms and the disease. The effects of the genetic polymorphisms were modeled assuming a co-dominant model, by considering the major homozygous as the reference level, the heterozygous as intermediate and the minor homozygous as the highest risk class (i.e., for the SNCA rs356219, creating an ordinal variable with three levels: TT, TC, CC, with the homozygote TT set as reference level).

Candidate variables were chosen based on the knowledge/hypotheses of risk factors and confounders for PD. The final adjusted model included variables for age, gender (male vs. female), smoking habits (ever/never), positive family history for PD or tremors, being born in a farm and being born in the province of Brescia (vs. outside the province of Brescia).

Age categories were defined as quartiles: $(65,72],(72,78]$, $(78,97]$, with reference quartile $[40,65]$. We did not categorize age in decades because only 25 subjects were in the reference 40-50 class, and therefore the estimates of the contrasts with the baseline with the other strata would have resulted less accurate.

Kaplan Meier estimates and log-rank test were used to study the age at PD onset for the various SNCA rs356219 genotypes.
Analyses were performed using the R 3.6.1 (R Foundation for Statistical Computing).

\section{RESULTS}

Demographic characteristics and results from the interviews are displayed in Table 1. The number of enrolled cases and controls were, respectively, 432 and 444, yielding a total population of 876 subjects with participation rates of $75 \%$ for cases and $60 \%$ for controls. Most subjects were able to participate in the interviews alone, whereas 173 subjects (20\% of the total), including 132 cases and 41 controls, participated with some degree of assistance by a caregiver. The overall mean age of subjects was 71 years (71.5 for cases with PD, 74.3 for cases with Parkinsonism and 70 for controls, $p<0.001)$. More than $10 \%$ of the cases were younger than 60 at visit day while mean age at diagnosis of PD and Parkinsonism was 65.9 (SD 9.9), and 7.5\% were younger than 50 and still actively employed. Ten cases were employed in job sectors with potential exposure to neurotoxic agents such as metallurgy, agriculture and constructions, at the time of diagnosis (data not shown). The diagnosis included Idiopathic $\mathrm{PD}$ in 334 cases $(77.3 \%$, with average age at onset of 65.2 years), and Parkinsonism in 98 cases $(22.7 \%$, with average age at diagnosis of 68.3 years; Parkinsonism subgroups are reported in Table 1).

Regarding the subtypes of motor symptoms, 173 subjects ( $40 \%$ of cases) presented with the akinetic-rigid form of PD, 233 (53.9\%) presented with the tremor-dominant PD, and 26 cases presented with a mixed phenotype.

Family history for PD or tremor, metal exposure, being born in a farmhouse and in the province of Brescia were more predominant among cases (both $\mathrm{PD}$ and Parkinsonism) than controls (all $P<0.01$ ). Prevalence of subjects who ever smoked was higher among controls, confirming previous observations (43) but not statistically significant $(P=0.198)$.

We did not find deviations of Hardy-Weinberg equilibrium for any of the SNP studied here. Genotype frequencies of SNPs among cases and controls are reported in Table 2. Only SNCA rs356219 showed a marginally significant difference in genotype frequencies between PD, Parkinsonism cases and controls with higher frequencies of the rare allele (C) among cases. Also, in the multinomial regression, when adjusting for all covariates, the only significant SNP associated with PD and Parkinsonism was SNCA rs356219 (Table 3). Moreover, rs356219 CC carriers developed PD and Parkinsonism earlier when compared with the other subjects. The median age at the onset of $\mathrm{PD}$ and Parkinsonism was 64 years for the CC carriers and 68 for both the TC and TT (p at the Log-rank test 0.048) (Supplementary Figure 1).

Results from multinomial regression analyses of risk factors vs. PD and Parkinsonism when considering SNCA rs356219 are reported in Table 4. We observed a significantly increased odds ratios for PD and Parkinsonism with family history of $\mathrm{PD}$ or tremor $(\mathrm{OR}=4.23 ; \mathrm{OR}=4.3$ respectively $), S N C A$ 
TABLE 1 | Socio-demographics, lifestyle habits and exposures.

\begin{tabular}{|c|c|c|c|c|c|}
\hline & Controls $(N=444)$ & PD $(N=334)$ & Parkinsonism $(N=98)$ & Total $(N=876)$ & $P$-value \\
\hline Sex & & & & & 0.906 \\
\hline $\mathrm{F}$ & $174(39.2 \%)$ & $126(37.7 \%)$ & $37(37.8 \%)$ & 337 (38.5\%) & \\
\hline M & $270(60.8 \%)$ & 208 (62.3\%) & $61(62.2 \%)$ & $539(61.5 \%)$ & \\
\hline Age & & & & & $<0.001$ \\
\hline Mean (SD) & $70.0(9.8)$ & $71.5(9.9)$ & $74.3(7.5)$ & $71.1(9.7)$ & \\
\hline \multicolumn{6}{|l|}{ Age at diagnosis } \\
\hline Mean (SD) & & $65.2(10.2)$ & $68.3(8.5)$ & $65.9(9.9)$ & \\
\hline \multicolumn{6}{|l|}{ Age $<50$ at diagnosis } \\
\hline No & & 294 (91.0\%) & $87(97.8 \%)$ & $381(92.5 \%)$ & \\
\hline Yes & & $29(9.0 \%)$ & $2(2.2 \%)$ & $31(7.5 \%)$ & \\
\hline Familiarity for PD or tremors & & & & & $<0.001$ \\
\hline No & 393 (95.9\%) & $246(83.4 \%)$ & 73 (84.9\%) & 712 (90.0\%) & \\
\hline Yes & $17(4.1 \%)$ & $49(16.6 \%)$ & $13(15.1 \%)$ & 79 (10.0\%) & \\
\hline Smoking habits & & & & & 0.198 \\
\hline Ever & 204 (46.2\%) & 133 (39.9\%) & $40(40.8 \%)$ & 377 (43.2\%) & \\
\hline Never & $238(53.8 \%)$ & $200(60.1 \%)$ & $58(59.2 \%)$ & $496(56.8 \%)$ & \\
\hline Exposure to metals & & & & & 0.001 \\
\hline No & 404 (94.0\%) & $283(86.0 \%)$ & $87(90.6 \%)$ & $774(90.5 \%)$ & \\
\hline Yes & $26(6.0 \%)$ & $46(14.0 \%)$ & $9(9.4 \%)$ & $81(9.5 \%)$ & \\
\hline Born in the province of Brescia & & & & & 0.001 \\
\hline No & $68(15.5 \%)$ & $29(8.8 \%)$ & $5(5.1 \%)$ & $102(11.8 \%)$ & \\
\hline Yes & $370(84.5 \%)$ & $302(91.2 \%)$ & 93 (94.9\%) & 765 (88.2\%) & \\
\hline Born in a farmhouse & & & & & 0.003 \\
\hline No & $386(88.3 \%)$ & 267 (80.7\%) & $76(77.6 \%)$ & $729(84.2 \%)$ & \\
\hline Yes & $51(11.7 \%)$ & 64 (19.3\%) & $22(22.4 \%)$ & 137 (15.8\%) & \\
\hline \multicolumn{6}{|l|}{ Parkinsonisms } \\
\hline Parkinson's disease dementia & & & 35 (35.7\%) & 35 (35.7\%) & \\
\hline Cortico Basal Syndrome & & & $12(12.3 \%)$ & $12(12.3 \%)$ & \\
\hline Dementia with Lewy bodies & & & $11(11.2 \%)$ & $11(11.2 \%)$ & \\
\hline Progressive Supranuclear Palsy & & & $9(9.2 \%)$ & $9(9.2 \%)$ & \\
\hline Multiple-system atrophy parkinsonian & & & $5(5.1 \%)$ & $5(5.1 \%)$ & \\
\hline Multiple-system atrophy cerebellar dysfunction & & & $1(1.0 \%)$ & $1(1.0 \%)$ & \\
\hline Unkown type & & & $25(25.5 \%)$ & $25(25.5 \%)$ & \\
\hline
\end{tabular}

ANOVA and chi-squared test $p$-values are reported for continuous and categorical variable respectively.

rs356219 (OR $=2.03 \mathrm{CC}$ vs. TT for PD; OR $=2.48 \mathrm{CC}$ vs. $\mathrm{TT}, \mathrm{OR}=1.85 \mathrm{TC}$ vs. TT for Parkinsonism), being exposed to metals $(\mathrm{OR}=2.37$ for $\mathrm{PD})$, being born in a farm $(\mathrm{OR}=$ 1.77; $\mathrm{OR}=2.63$ for $\mathrm{PD}$ and Parkinsonism respectively) and being born in the province of Brescia ( $O R=1.7$ for $P D)$. An interaction term between SNCA gene and metal exposure was added only when considering PD cases since we had too few observations in each category for Parkinsonism (among subjects with Parkinsonism and exposed to metals there were one CC, three TC and 5 TT SNCA carriers, respectively). Results showed there were increased OR for TC and CC carriers exposed to metals (Table 4). Figure 1 shows the conditional OR of having PD depending by SNCA polymorphism and metal exposure fixing the other covariates values at reference value highlighting higher risk of PD among CC SNCA carriers and being exposed to metals. However, the interaction term was not statistically significant.

\section{DISCUSSION}

This study highlights the increased risk of PD in relation to exposure to metals and increased risk of Parkinsonism and $\mathrm{PD}$ in relation to a SCNA polymorphism. The role of genetics is further stressed by the significant effect of positive family history: among the putative risk factors, family history showed the strongest association with Parkinsonism and PD.

This study is consistent with earlier studies about exposure to metals and risk of Parkinsonism and PD where increased risk of $\mathrm{PD}$ have been associated with to occupational exposure to $\mathrm{Mn}, \mathrm{Pb}, \mathrm{Cu}$, and $\mathrm{Fe}$ (44) and Fe intake (45) (the first study recruited a total of 608 patients while the second study was a meta-analysis on a total of 126,507 subjects). Further, in the province of Brescia, exposure to Mn has been shown as potentially related to the increased risk of Parkinsonism and PD 
TABLE 2 | SNP frequency among cases and controls.

\begin{tabular}{|c|c|c|c|c|c|}
\hline & $\begin{array}{l}\text { Controls } \\
(N=444)\end{array}$ & $\begin{array}{c}\text { PD } \\
(N=334)\end{array}$ & $\begin{array}{l}\text { Parkinsonism } \\
\quad(N=98)\end{array}$ & $\begin{array}{c}\text { Total } \\
(N=876)\end{array}$ & $P$-valt \\
\hline \multicolumn{5}{|c|}{ SNCA rs356219 } & 0.054 \\
\hline$\pi$ & $181(42.6 \%)$ & $111(34.5 \%)$ & $30(32.6 \%)$ & $322(38.4 \%)$ & \\
\hline TC & $190(44.7 \%)$ & $150(46.6 \%)$ & $46(50.0 \%)$ & $386(46.0 \%)$ & \\
\hline CC & $54(12.7 \%)$ & $61(18.9 \%)$ & $16(17.4 \%)$ & $131(15.6 \%)$ & \\
\hline \multicolumn{5}{|c|}{ SLC39A8 rs13107325 } & 0.989 \\
\hline CC & $359(85.1 \%)$ & $276(85.7 \%)$ & 76 (85.4\%) & $711(85.4 \%)$ & \\
\hline CT & $60(14.2 \%)$ & 44 (13.7\%) & $12(13.5 \%)$ & $116(13.9 \%)$ & \\
\hline$\pi$ & $3(0.7 \%)$ & $2(0.6 \%)$ & $1(1.1 \%)$ & $6(0.7 \%)$ & \\
\hline \multicolumn{5}{|c|}{ SLC30A10 rs12064812 } & 0.849 \\
\hline$\pi$ & $206(48.7 \%)$ & $155(48.1 \%)$ & 44 (49.4\%) & 405 (48.6\%) & \\
\hline CT & $172(40.7 \%)$ & $133(41.3 \%)$ & $39(43.8 \%)$ & $344(41.2 \%)$ & \\
\hline CC & 45 (10.6\%) & 34 (10.6\%) & 6 (6.7\%) & 85 (10.2\%) & \\
\hline \multicolumn{5}{|c|}{ SLC30A10 rs22757007 } & 0.796 \\
\hline AA & 230 (54.5\%) & $178(55.5 \%)$ & 50 (56.2\%) & $458(55.0 \%)$ & \\
\hline$A C$ & $166(39.3 \%)$ & $117(36.4 \%)$ & $34(38.2 \%)$ & $317(38.1 \%)$ & \\
\hline $\mathrm{CC}$ & $26(6.2 \%)$ & $26(8.1 \%)$ & $5(5.6 \%)$ & 57 (6.9\%) & \\
\hline \multicolumn{5}{|c|}{ SLC30A10 rs1776029 } & 0.907 \\
\hline GG & $257(60.8 \%)$ & $191(59.3 \%)$ & $54(60.7 \%)$ & $502(60.2 \%)$ & \\
\hline GA & $143(33.8 \%)$ & $109(33.9 \%)$ & $31(34.8 \%)$ & $283(33.9 \%)$ & \\
\hline AA & $23(5.4 \%)$ & $22(6.8 \%)$ & $4(4.5 \%)$ & 49 (5.9\%) & \\
\hline \multicolumn{5}{|c|}{ ATP13A2 rs4920608 } & 0.114 \\
\hline$\pi$ & 46 (33.6\%) & 52 (39.4\%) & 9 (22.0\%) & 107 (34.5\%) & \\
\hline TC & $67(48.9 \%)$ & 66 (50.0\%) & $22(53.7 \%)$ & 155 (50.0\%) & \\
\hline CC & $24(17.5 \%)$ & $14(10.6 \%)$ & $10(24.4 \%)$ & $48(15.5 \%)$ & \\
\hline \multicolumn{5}{|c|}{ ATP13A2 rs2871776 } & 0.168 \\
\hline GG & $122(28.8 \%)$ & 85 (26.0\%) & 37 (38.5\%) & 244 (28.8\%) & \\
\hline$A G$ & 206 (48.6\%) & $159(48.6 \%)$ & $42(43.8 \%)$ & 407 (48.1\%) & \\
\hline AA & $96(22.6 \%)$ & 83 (25.4\%) & $17(17.7 \%)$ & $196(23.1 \%)$ & \\
\hline \multicolumn{5}{|c|}{ DMT1 rs224589 } & 0.861 \\
\hline $\mathrm{CC}$ & $248(58.5 \%)$ & $192(58.7 \%)$ & $51(53.7 \%)$ & 491 (58.0\%) & \\
\hline CA & $142(33.5 \%)$ & $113(34.6 \%)$ & $36(37.9 \%)$ & 291 (34.4\%) & \\
\hline AA & 34 (8.0\%) & 22 (6.7\%) & 8 (8.4\%) & 64 (7.6\%) & \\
\hline
\end{tabular}

Chi-squared test $p$-values are reported.

based on ecological observation (1). We were not able to consider exposure to single metals since for each element we had too few observations for cases and controls. However, this association was mainly driven by the exposure to $\mathrm{Pb}$ which was the most frequent element to which the subjects were exposed to and it is also known as the most dangerous for PD among all metals (46). Our results are also consistent with previous studies on the increased risk of PD and Parkinsonism due to pesticide exposure (47-50) that we identified through the fact of being born in a farm.

Discovery of mutations in genes causing inherited forms of $\mathrm{PD}$ and epidemiological, in vitro, and in vivo evidence of environmental risk factors have improved the knowledge of mechanisms underlying PD. Most cases are likely due to
TABLE 3 | Results of multinomial regression analysis to test for the association between each polymorphism and PD and Parkinsonism adjusting for all the risk factors (age, gender, smoking status, PD or tremor familiarity, being born in a farm, being exposed to metals and being born in the province of Brescia).

\begin{tabular}{|c|c|c|c|c|c|c|}
\hline \multirow[b]{2}{*}{ Variables } & \multicolumn{3}{|c|}{ PD } & \multicolumn{3}{|c|}{ Parkinsonism } \\
\hline & OR & $95 \% \mathrm{Cl}$ & $\boldsymbol{P}$ & OR & $95 \% \mathrm{Cl}$ & $P$ \\
\hline \multicolumn{7}{|c|}{ SNCA rs356219 } \\
\hline TC vs. TT & 1.24 & $0.87-1.78$ & 0.230 & 1.85 & $1.05-3.29$ & 0.035 \\
\hline CC vs. TT & 2.03 & $1.25-3.30$ & 0.004 & 2.48 & $1.15-5.33$ & 0.020 \\
\hline \multicolumn{7}{|c|}{ SLC39A8 rs13107325 } \\
\hline CT vs. CC & 1.01 & $0.64-1.61$ & 0.956 & & & \\
\hline Tा vs. CC & 0.53 & $0.05-5.47$ & 0.594 & & & \\
\hline \multicolumn{7}{|c|}{ SLC30A10 rs12064812 } \\
\hline CT vs. TT & 1.09 & $0.77-1.54$ & 0.620 & 1.19 & $0.70-2.03$ & 0.522 \\
\hline CC vs. $\pi$ & 0.93 & $0.54-1.60$ & 0.797 & 0.71 & $0.27-1.83$ & 0.476 \\
\hline
\end{tabular}

SLC30A10 rs22757007

$\begin{array}{lllllll}\text { AC vs. AA } & 0.93 & 0.66-1.31 & 0.673 & 0.92 & 0.54-1.57 & 0.765\end{array}$

$\begin{array}{lllllll}\text { CC vs. AA } & 0.95 & 0.49-1.83 & 0.875 & 0.45 & 0.13-1.62 & 0.223\end{array}$

SLC30A10 rs1776029

$\begin{array}{lllllll}\text { GA vs. GG } & 1.05 & 0.74-1.49 & 0.768 & 1.00 & 0.58-1.73 & 0.991\end{array}$

AA vs. GG

$\begin{array}{llllll}1.05 & 0.74-1.49 & 0.768 & 1.00 & 0.58-1.73 & 0.991 \\ 1.00 & 0.50-2.00 & 0.991 & 0.33 & 0.07-1.49 & 0.149\end{array}$

ATP13A2 rs4920608

TC vs. Tा

CC vs. TT

ATP13A2 rs2871776

AG vs. GG

AA vs. GG

DMT1 rs224589

CA vs. CC

AA vs. CC

$\begin{array}{llllll}0.91 & 0.50-1.67 & 0.768 & 2.44 & 0.88-6.74 & 0.086\end{array}$

$\begin{array}{lllllll}0.45 & 0.18-1.13 & 0.088 & 3.29 & 0.96-11.28 & 0.058\end{array}$

$\begin{array}{llllll}1.14 & 0.77-1.67 & 0.520 & 0.78 & 0.45-1.35 & 0.373\end{array}$

$1.18 \quad 0.76-1.86 \quad 0.458 \quad 0.57 \quad 0.28-1.17 \quad 0.125$

$\begin{array}{llllll}1.05 & 0.74-1.49 & 0.776 & 1.15 & 0.68-1.95 & 0.609\end{array}$

$0.96 \quad 0.52-1.79 \quad 0.900 \quad 1.30 \quad 0.52-3.25 \quad 0.568$

Adjusted regression odds ratios, $95 \% \mathrm{Cl}$, and their p-values are shown. For SLC39A8 rs13107325 only the association with PD is shown since carriers for the $\pi$ genotype were too few for Parkinsonism. p-values below 0.05 are shown in bold.

different combinations of environmental exposures and genetic susceptibility (35).

SNCA is a key gene in the pathophysiology of Parkinsonism/PD and was the first autosomal dominant gene to be identified. Rare missense mutations as well as gene triplications in SNCA have been identified as causes for rare familial forms of $\mathrm{PD}$, mediating disease through changes in protein fibrillation or higher expression of the protein, alpha-synuclein (51-53). These mutations account for only a small proportion of PD cases. More common genetic variants, although neither necessary nor sufficient to lead to disease, also have a modest effect on increasing the transcription of SNCA. Genome-wide association studies have demonstrated association between SNCA common variants and susceptibility to sporadic PD disease (54). In line with our findings, a recent meta-analysis showed that rs356219 is associated with increased risk of PD (55) (see ref in the comment field), while a recent study found that SNCA can modulate the PD age at onset (56).

Interactions between $\mathrm{Mn}$ and SNCA has been studied extensively in in vivo and in vitro studies (32). The neurotoxicity 
TABLE 4 | Results of multinomial and logistic regression analysis to test for the association between risk factors (age, gender, smoking status, PD or tremor familiarity, SNCA rs356219, being born in a farm, being exposed to metals and being born in the province of Brescia) and PD and Parkinsonism.

\begin{tabular}{|c|c|c|c|c|c|c|}
\hline \multirow[b]{2}{*}{ Variables } & \multicolumn{3}{|c|}{ Multinomial regression } & \multicolumn{3}{|c|}{ Logistic regression } \\
\hline & OR & $95 \% \mathrm{Cl}$ & $P$ & OR & $95 \% \mathrm{Cl}$ & $P$ \\
\hline \multicolumn{7}{|l|}{ PD } \\
\hline $\begin{array}{l}\text { Age (q.les) }[65,72] \text { vs. } \\
{[40,65]}\end{array}$ & 1.18 & $0.76-1.83$ & 0.452 & 1.22 & $0.78-1.89$ & 0.381 \\
\hline $\begin{array}{l}\text { Age (q.les) }[72,78] \text { vs. } \\
{[40,65]}\end{array}$ & 1.45 & $0.92-2.30$ & 0.112 & 1.45 & $0.91-2.30$ & 0.118 \\
\hline $\begin{array}{l}\text { Age (q.les) }[78,97] \text { vs. } \\
{[40,65]}\end{array}$ & 1.83 & $1.14-2.93$ & 0.012 & 1.84 & $1.14-2.96$ & 0.012 \\
\hline Gender (M vs. F) & 1.03 & $0.72-1.46$ & 0.882 & 1.03 & $0.72-1.46$ & 0.891 \\
\hline $\begin{array}{l}\text { Smoking (ever vs. } \\
\text { never) }\end{array}$ & 0.73 & $0.52-1.03$ & 0.076 & 0.70 & $0.50-1.00$ & 0.051 \\
\hline $\begin{array}{l}\text { Familiarity for PD or } \\
\text { tremor }\end{array}$ & 4.23 & $2.34-7.65$ & $<0.001$ & 4.26 & $2.34-7.75$ & $<0.001$ \\
\hline Born in the BS Province & 1.70 & $1.00-2.87$ & 0.048 & 1.71 & $1.01-2.89$ & 0.047 \\
\hline Born in a farm & 1.77 & $1.10-2.85$ & 0.018 & 1.79 & $1.11-2.89$ & 0.017 \\
\hline $\begin{array}{l}\text { Being exposed to } \\
\text { metals }\end{array}$ & 2.37 & $1.34-4.21$ & 0.003 & 1.85 & $0.70-4.86$ & 0.212 \\
\hline $\begin{array}{l}\text { SNCA rs356219 (TC } \\
\text { vs. TT) }\end{array}$ & 1.24 & $0.87-1.78$ & 0.230 & 1.20 & $0.82-1.74$ & 0.347 \\
\hline $\begin{array}{l}\text { SNCA rs356219 (CC } \\
\text { vs. TT) }\end{array}$ & 2.03 & $1.25-3.30$ & 0.004 & 1.93 & $1.15-3.21$ & 0.012 \\
\hline $\begin{array}{l}\text { Exposed to metals* } \\
\text { SNCA (TC vs. TT) }\end{array}$ & & & & 1.39 & $0.40-4.85$ & 0.603 \\
\hline $\begin{array}{l}\text { Exposed to metals* } \\
\text { SNCA (CC vs. TT) }\end{array}$ & & & & 1.63 & $0.29-9.03$ & 0.575 \\
\hline \multicolumn{7}{|l|}{ Parkinsonism } \\
\hline $\begin{array}{l}\text { Age (q.les) }(65,72] \text { vs. } \\
{[40,65]}\end{array}$ & 2.75 & $1.20-6.34$ & 0.017 & & & \\
\hline $\begin{array}{l}\text { Age (q.les) }(72,78] \text { vs. } \\
{[40,65]}\end{array}$ & 4.22 & $1.84-9.71$ & 0.001 & & & \\
\hline $\begin{array}{l}\text { Age (q.les) }(78,97] \text { vs. } \\
{[40,65]}\end{array}$ & 4.97 & $2.13-11.59$ & $<0.001$ & & & \\
\hline Gender (M vs. F) & 1.12 & $0.64-1.95$ & 0.693 & & & \\
\hline $\begin{array}{l}\text { Smoking (ever vs. } \\
\text { never) }\end{array}$ & 1.12 & $0.65-1.91$ & 0.690 & & & \\
\hline $\begin{array}{l}\text { Familiarity for PD or } \\
\text { tremor }\end{array}$ & 4.30 & $1.94-9.52$ & $<0.001$ & & & \\
\hline Born in the BS Province & 2.27 & $0.86-5.99$ & 0.099 & & & \\
\hline Born in a farm & 2.63 & $1.40-4.95$ & 0.003 & & & \\
\hline $\begin{array}{l}\text { Being exposed to } \\
\text { metals }\end{array}$ & 1.36 & $0.53-3.44$ & 0.521 & & & \\
\hline $\begin{array}{l}\text { SNCA rs356219 (TC } \\
\text { vs. TT) }\end{array}$ & 1.85 & 1.05-3.29 & 0.035 & & & \\
\hline $\begin{array}{l}\text { SNCA rs356219 (CC } \\
\text { vs. Tा) }\end{array}$ & 2.48 & $1.15-5.33$ & 0.020 & & & \\
\hline
\end{tabular}

Adjusted regression odds ratios, 95\% Cl, and their p-values are shown. p-values below 0.05 are shown in bold. The symbol * represents the product between metal exposure and SNCA, for more clarity we can substitute it with $x$.

of SNCA and the role of Mn seem to be intensity and time depending $(31,32)$. SNCA may be involved in the regulation of neuronal manganese and actually be neuroprotective against acute manganese exposure (33). Chronic manganese exposure has been shown to promote alpha-Synuclein aggregation and toxicity in dopaminergic cells $(34,57,58)$.

We only observed a marginally significant influence (but with high uncertainty due to the wide $\mathrm{CI}$ ) from polymorphism in ATP13A2 (also known as PARK9) rs4920608 on the risk of developing PD and Parkinsonism. The same polymorphisms that were assessed here have shown gene-environment interactions with $\mathrm{Mn}$ on Parkinsonism in other studies (25). A recessive mutation in the ATP13A2 encoding for the lysosomal Ptype ATPase "PARK9" causes the inherited parkinsonian syndromes 'Parkinson's disease 9' (or Kufor-Rakeb syndrome, PARK9, \#606693). Loss of ATP13A2 function in mice causes sensorimotor deficits, increased sensitivity to manganese and accumulation of alpha-synuclein (35).

No associations were observed between polymorphisms in SLC30A10 or SLC39A8 and PD or Parkinsonism in this study. SLC30A10 and SLC39A8 are both involved in Mn transport $(59,60)$ and polymorphisms in these genes have been associated with blood Mn concentrations (27, 60, 61) and linked to neurological outcomes $(27,62,63)$ but so far not to PD. Lack of evidence of statistical interaction in this, as well as other studies, may be due to the low frequencies of subjects exposed to metals and in each polymorphism variant and does not rule out biological interaction (64). One should also be aware that statistical interaction depends upon the statistical model used to represent the relationships between the risk factors and the disease and that its representation is scale-dependent. In a generalized linear model interaction is defined as a deviation from additivity of the effects of the risk factors, measured in the scale of the linear predictor. According to an inherently multiplicative model, as the logistic regression model is, the contemporaneous presence of genetic and environmental risk factors produces a multiplication of the risk, calculated on an OR scale. Furthermore, as this is a case-control study, this study has the disadvantage of recall bias. While case-control studies are ideal to study disease with a long latency period, such as Parkinsonism/PD, participants in this study may have been subjected to recall bias when asked about metal exposure. We enrolled considerable number of subjects who participated with the assistance of a caregiver especially among cases $(30.5 \%$ while $9.2 \%$ among controls), however only $5.3 \%$ cases and $1.6 \%$ controls needed full caregivers' assistance. To minimize the recall bias, we conducted direct face-to-face interviews in the participating hospitals. In addition, the measurement for metal exposure was a crude yes or no. Lack of a precise measurement among participants may have resulted in nondifferential misclassification of exposure, which could have biased the results toward the null. In addition, there may be other biological factors that are playing a role in the interaction between genetics and the outcome of Parkinsonism and PD that are not yet identified. The strength of this study is the homogeneity of the study population as well as the completion of data on a large set of known risk factors for a uniquely susceptible population with a rare exposure.

Through this work we were able to assess that lifetime exposure to metals and genetic predisposition in SNCA 


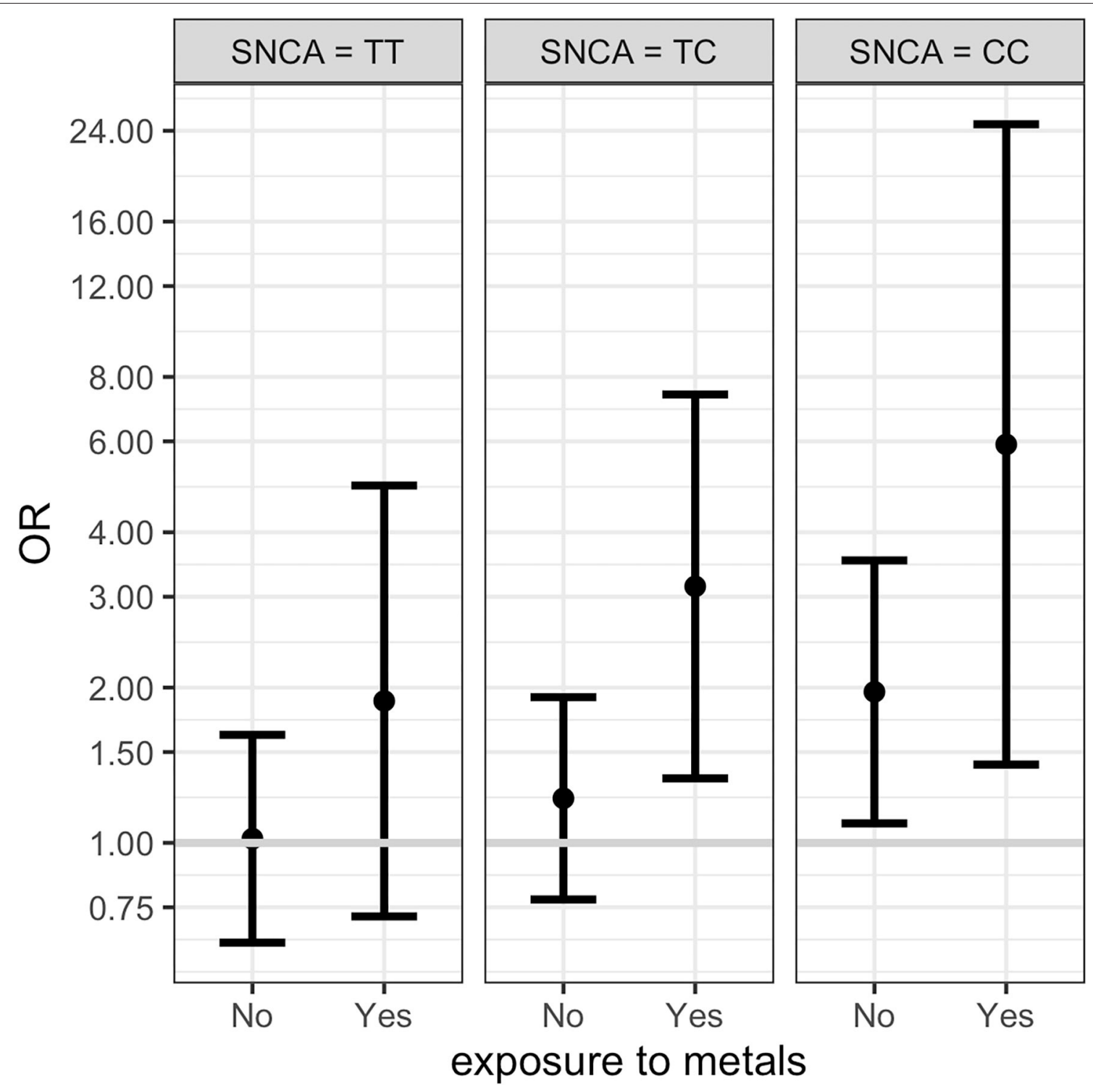

FIGURE 1 | Conditional ORs of having PD depending by SNCA rs356219 and metal exposure (fixing the other covariates values at reference value) estimated from the multinomial regression. The first plot represents the conditional OR for subjects with SNCA TT polymorphism non-exposed and exposed to metals. The second and third columns shows the conditional ORs for TC and CC polymorphisms respectively. $95 \% \mathrm{Cl}$ are represented by the bars.

are determinants of $\mathrm{PD}$ and parkinsonism in the highly industrialized area of Brescia, Italy.

\section{DATA AVAILABILITY STATEMENT}

The raw data supporting the conclusions of this article will be made available by the authors, without undue reservation.

\section{ETHICS STATEMENT}

The studies involving human participants were reviewed and approved by Ethical Committee of the Spedali Civili, Brescia. The patients/participants provided their written informed consent to participate in this study.

\section{AUTHOR CONTRIBUTIONS}

RL: overall coordination. SG, SR, and DH: statistical analysis. $\mathrm{KB}$, LC, CP, and KW: genetic measurement/interpretation. MC, PC, MO, FP, MR, and MT: data collection. UG: epidemiological study design. $\mathrm{DH}, \mathrm{APi}$, and $\mathrm{APa}$ paper revision/interpretation. DP: occupational history coding and study coordinator. All authors contributed to the article and approved the submitted version. 


\section{FUNDING}

This work was supported by The Italian Work Compensation Institute INAIL 60002.02/07/2012; the National Institute of Health: R01ES019222-06A1, R56-R01ES019222-06, P30 ES023515; the European Union Sixth Framework Program: FOODCT-2006-016253; the Swedish Research Council for Health, Working Life and Welfare (FORTE), Hedlunds foundation, Karolinska Institutet; the University of Brescia, Italy: UNBSCLE 9015.

\section{REFERENCES}

1. Lucchini RG, Albini E, Benedetti L, Borghesi S, Coccaglio R, Malara EC, et al. High prevalence of Parkinsonian disorders associated to manganese exposure in the vicinities of ferroalloy industries. Am J Ind Med. (2007) 50:788-800. doi: 10.1002/ajim.20494

2. Squitti R, Gorgone G, Panetta V, Lucchini R, Bucossi S, Albini E, et al. Implications of metal exposure and liver function in Parkinsonian patients resident in the vicinities of ferroalloy plants. J Neural Transm. (2009) 116:1281-7. doi: 10.1007/s00702-009-0283-0

3. Lucchini R, Albini E, Benedetti L, Zoni S, Caruso A, Nan E, et al. Neurological and neuropsychological features in Parkinsonian patients exposed to neurotoxic metals. G Ital Med Lav Ergon. (2007) 29(3 Suppl):280-1.

4. Lucchini R, Squitti R, Albini E, Benedetti L, Borghesi S, Nan E. Manganese exposure as a determinant of Parkinsonian damage. Cell Biol Toxicol. (2008) 24:445-8. doi: 10.1007/s12017-009-8083-0

5. Borgese L, Federici S, Zacco A, Gianoncelli A, Rizzo L, Smith DR, et al. Metal fractionation in soils and assessment of environmental contamination in Vallecamonica, Italy. Environ Sci Pollut Res Int. (2013) 20:5067-75. doi: $10.1007 /$ s11356-013-1473-8

6. Pavilonis BT, Lioy PJ, Guazzetti S, Bostick BC, Donna F, Peli M, et al. Manganese concentrations in soil and settled dust in an area with historic ferroalloy production. J Expo Sci Environ Epidemiol. (2015) 25:443-50. doi: $10.1038 /$ jes.2014.70

7. Lucas EL, Bertrand P, Guazzetti S, Donna F, Peli M, Jursa TP, et al. Impact of ferromanganese alloy plants on household dust manganese levels: implications for childhood exposure. Environ Res. (2015) 138:279-90. doi: 10.1016/j.envres.2015.01.019

8. Ferri R, Donna F, Smith DR, Guazzetti S, Zacco A, Rizzo L, et al. Heavy metals in soil and salad in the proximity of historical ferroalloy emission. J Environ Prot. (2012) 3:374-85. doi: 10.4236/jep.2012.35047

9. Ferri R, Hashim D, Smith DR, Guazzetti S, Donna F, Ferretti E, et al. Metal contamination of home garden soils and cultivated vegetables in the province of Brescia, Italy: implications for human exposure. Sci Total Environ. (2015) 518-9:507-17. doi: 10.1016/j.scitotenv.2015. 02.072

10. Bilo F, Borgese L, Wambui A, Assi A, Zacco A, Federici S, et al. Comparison of multiple X-ray fluorescence techniques for elemental analysis of particulate matter collected on air filters. J Aerosol Sci. (2018) 122:1-10. doi: 10.1016/j.jaerosci.2018.05.003

11. Borgese L, Salmistraro M, Gianoncelli A, Zacco A, Lucchini R, Zimmerman $\mathrm{N}$, et al. Airborne particulate matter (PM) filter analysis and modeling by total reflection X-ray fluorescence (TXRF) and X-ray standing wave (XSW). Talanta. (2012) 89:99-104. doi: 10.1016/j.talanta.2011.11.073

12. Borgese L, Zacco A, Bontempi E, Colombi P, Bertuzzi R, Ferretti E, et al. Total reflection of X-ray fluorescence (TXRF): a mature technique for environmental chemical nanoscale metrology. Meas Sci Technol. (2009) 20. doi: 10.1088/0957-0233/20/8/084027

13. Borgese L, Zacco A, Pal S, Bontempi E, Lucchini R, Zimmerman N, et al. A new non-destructive method for chemical analysis of particulate matter filters: the case of manganese air pollution in Vallecamonica (Italy). Talanta. (2011) 84:192-8. doi: 10.1016/j.talanta.2010.12.048
ACKNOWLEDGMENTS

We would like to thank Ilaria Zerbini and Gaia C. V. Viola from the University of Brescia for their work on genetic assessment.

\section{SUPPLEMENTARY MATERIAL}

The Supplementary Material for this article can be found online at: https://www.frontiersin.org/articles/10.3389/fneur. 2020.556337/full\#supplementary-material

14. Zacco A, Resola S, Lucchini R, Albini E, Zimmerman N, Guazzetti S, et al Analysis of settled dust with X-ray fluorescence for exposure assessment of metals in the province of Brescia, Italy. J Environ Monit. (2009) 11:1579-85. doi: 10.1039/b906430c

15. Butler RN, Sprott R, Warner H, Bland J, Feuers R, Forster M, et al. Biomarkers of aging: from primitive organisms to humans. J Gerontol A Biol Sci Med Sci. (2004) 59:B560-7. doi: 10.1093/gerona/59.6.B560

16. Lucchini RG, Guazzetti S, Zoni S, Donna F, Peter S, Zacco A, et al. Tremor, olfactory and motor changes in Italian adolescents exposed to historical ferro-manganese emission. Neurotoxicology. (2012) 33:687-96. doi: 10.1016/j.neuro.2012.01.005

17. Iannilli E, Gasparotti R, Hummel T, Zoni S, Benedetti C, Fedrighi C, et al. Effects of manganese exposure on olfactory functions in teenagers: a pilot study. PLoS ONE. (2016) 11:0144783. doi: 10.1371/journal.pone.0144783

18. Bauer JA, Claus Henn B, Austin C, Zoni S, Fedrighi C, Cagna G, et al. Manganese in teeth and neurobehavior: Sex-specific windows of susceptibility. Environ Int. (2017) 108:299-308. doi: 10.1016/j.envint.2017.08.013

19. Chiu YM, Claus Henn B, Hsu HL, Pendo MP, Coull BA, Austin C, et al. Sex differences in sensitivity to prenatal and early childhood manganese exposure on neuromotor function in adolescents. Environ Res. (2017) 159:458-65. doi: 10.1016/j.envres.2017.08.035

20. Lucchini R, Selis L, Folli D, Apostoli P, Mutti A, Vanoni O, et al. Neurobehavioral effects of manganese in workers from a ferroalloy plant after temporary cessation of exposure. Scand J Work Environ Health. (1995) 21:143-9. doi: 10.5271/sjweh.1369

21. Lucchini R, Apostoli P, Perrone C, Placidi D, Albini E, Migliorati P, et al. Longterm exposure to low levels of manganese oxides and neurofunctional changes in ferroalloy workers. Neurotoxicology. (1999) 20:287-97.

22. Lucchini R, Albini E, Placidi D, Gasparotti R, Pigozzi MG, Montani G, et al. Brain magnetic resonance imaging and manganese exposure. Neurotoxicology. (2000) 21:769-75. doi: 10.1016/j.neuro.2006.08.005

23. Zoni S, Bonetti G, Lucchini R. Olfactory functions at the intersection between environmental exposure to manganese and Parkinsonism. J Trace Elem Med Biol. (2012) 26:179-82. doi: 10.1016/j.jtemb.2012.04.023

24. Lucchini RG, Guazzetti S, Zoni S, Benedetti C, Fedrighi C, Peli M, et al. Neurofunctional dopaminergic impairment in elderly after lifetime exposure to manganese. Neurotoxicology. (2014) 45:309-17. doi: 10.1016/j.neuro.2014.05.006

25. Rentschler G, Covolo L, Haddad A, Lucchini R, Zoni S, Broberg K. ATP13A2 (PARK9) polymorphisms influence the neurotoxic effects of manganese. Neurotoxicology. (2012) 33:697-702. doi: 10.1016/j.neuro.2012.01.007

26. Wahlberg K, Arora M, Curtin A, Curtin P, Wright RO, Smith DR, et al. Polymorphisms in manganese transporters show developmental stage and sex specific associations with manganese concentrations in primary teeth. Neurotoxicology. (2018) 64:103-9. doi: 10.1016/j.neuro.2017.09.003

27. Wahlberg K, Kippler M, Alhamdow A, Rahman SM, Smith DR, Vahter M, et al. Common polymorphisms in the solute carrier SLC30A10 are associated with blood manganese and neurological function. Toxicol Sci. (2016) 149:47383. doi: $10.1093 /$ toxsci/kfv252

28. Wahlberg KE, Guazzetti S, Pineda D, Larsson SC, Fedrighi C, Cagna G, et al. Polymorphisms in manganese transporters. Front Genet. (2018) 9:664. doi: 10.3389/fgene.2018.00664 
29. Broberg K, Taj T, Guazzetti S, Peli M, Cagna G, Pineda D, et al. Manganese transporter genetics and sex modify the association between environmental manganese exposure and neurobehavioral outcomes in children. Environ Int. (2019) 130:104908. doi: 10.1016/j.envint.2019.104908

30. Mezzaroba L, Alfieri DF, Colado Simão AN, Vissoci Reiche EM. The role of zinc, copper, manganese and iron in neurodegenerative diseases. Neurotoxicology. (2019) 74:230-41. doi: 10.1016/j.neuro.2019.07.007

31. Peres TV, Schettinger MR, Chen P, Carvalho F, Avila DS, Bowman AB, et al. Manganese-induced neurotoxicity: a review of its behavioral consequences and neuroprotective strategies. BMC Pharmacol Toxicol. (2016). 17:57. doi: 10.1186/s40360-016-0099-0

32. Peres TV, Parmalee NL, Martinez-Finley EJ, Aschner M. Untangling the manganese- $\alpha$-synuclein web. Front Neurosci. (2016) 10:364. doi: 10.3389/fnins.2016.00364

33. Dučić T, Carboni E, Lai B, Chen S, Michalke B, Lázaro DF, et al. Alphasynuclein regulates neuronal levels of manganese and calcium. ACS Chem Neurosci. (2015) 6:1769-79. doi: 10.1021/acschemneuro.5b00093

34. Harischandra DS, Jin H, Anantharam V, Kanthasamy A, Kanthasamy AG. $\alpha-$ Synuclein protects against manganese neurotoxic insult during the early stages of exposure in a dopaminergic cell model of Parkinson's disease. Toxicol Sci. (2015). 143:454-68. doi: 10.1093/toxsci/kfu247

35. Fleming SM. Mechanisms of gene-environment interactions in Parkinson's disease. Curr Environ Health Rep. (2017) 4:192-9. doi: 10.1007/s40572-017-0143-2

36. Cicero CE, Mostile G, Vasta R, Rapisarda V, Signorelli SS, Ferrante M, et al. Metals and neurodegenerative diseases. A systematic review. Environ Res. (2017) 159:82-94. doi: 10.1016/j.envres.2017.07.048

37. Vlaar T, Kab S, Schwaab Y, Fréry N, Elbaz A, Moisan F. Association of Parkinson's disease with industry sectors: a French nationwide incidence study. Eur J Epidemiol. (2018) 33:1101-11. doi: 10.1007/s10654-018-0399-3

38. Williams DR, Litvan I. Parkinsonian syndromes. Continuum. (2013) 19:1189212. doi: 10.1212/01.CON.0000436152.24038.e0

39. Postuma RB, Berg D, Stern M, Poewe W, Olanow CW, Oertel W, et al. MDS clinical diagnostic criteria for Parkinson's disease. Mov Disord. (2015) 30:1591-601. doi: 10.1002/mds.26424

40. Suleiman J, El-Hattab AW. ATP13A2-related juvenile-onset Parkinson disease. Brain Dev. (2019) 41:223. doi: 10.1016/j.braindev.2018.08.002

41. Zhang Y, Shu L, Sun Q, Pan H, Guo J, Tang B. A comprehensive analysis of the association between. Front Mol Neurosci. (2018) 11:391. doi: 10.3389/fnmol.2018.00391

42. Fan Q, Zhou Y, Yu C, Chen J, Shi X, Zhang Y, et al. Cross-sectional study of expression of divalent metal transporter-1, transferrin, and hepcidin in blood of smelters who are occupationally exposed to manganese. PeerJ. (2016) 4:e2413. doi: $10.7717 /$ peerj.2413

43. Lee PC, Ahmed I, Loriot MA, Mulot C, Paul KC, Bronstein JM, et al. Smoking and Parkinson disease: evidence for gene-by-smoking interactions. Neurology. (2018) 90:e583-92. doi: 10.1212/WNL.000000000 0004953

44. Gorell JM, Johnson CC, Rybicki BA, Peterson EL, Kortsha GX, Brown GG, et al. Occupational exposures to metals as risk factors for Parkinson's disease. Neurology. (1997) 48:650-8. doi: 10.1212/WNL.48.3.650

45. Cheng P, Yu J, Huang W, Bai S, Zhu X, Qi Z, et al. Dietary intake of iron, zinc, copper, and risk of Parkinson's disease: a meta-analysis. Neurol Sci. (2015) 36:2269-75. doi: 10.1007/s10072-015-2349-0

46. Gunnarsson LG, Bodin L. Occupational exposures and neurodegenerative diseases-a systematic literature review and meta-analyses. Int J Environ Res Public Health. (2019) 16:337. doi: 10.3390/ijerph16030337

47. Yan D, Zhang Y, Liu L, Shi N, Yan H. Pesticide exposure and risk of Parkinson's disease: dose-response meta-analysis of observational studies. Regul Toxicol Pharmacol. (2018) 96:57-63. doi: 10.1016/j.yrtph.2018.05.005

48. Gunnarsson LG, Bodin L. Parkinson's disease and occupational exposures: a systematic literature review and meta-analyses. Scand J Work Environ Health. (2017) 43:197-209. doi: 10.5271/sjweh.3641

49. Dorsey ER, Sherer T, Okun MS, Bloem BR. The emerging evidence of the parkinson pandemic. J Parkinsons Dis. (2018) 8:S3-8. doi: $10.3233 /$ JPD-181474
50. Marras C, Canning CG, Goldman SM. Environment, lifestyle, and Parkinson's disease: implications for prevention in the next decade. Mov Disord. (2019) 34:801-11. doi: 10.1002/mds. 27720

51. Krüger R, Kuhn W, Müller T, Woitalla D, Graeber M, Kösel S, et al. Ala30Pro mutation in the gene encoding alpha-synuclein in Parkinson's disease. Nat Genet. (1998) 18:106-8. doi: 10.1038/ng0298-106

52. Polymeropoulos MH, Lavedan C, Leroy E, Ide SE, Dehejia A, Dutra A, et al. Mutation in the alpha-synuclein gene identified in families with Parkinson's disease. Science. (1997) 276:2045-7. doi: 10.1126/science.276.5321.2045

53. Singleton AB, Farrer M, Johnson J, Singleton A, Hague S, Kachergus J, et al. alpha-Synuclein locus triplication causes Parkinson's disease. Science. (2003) 302:841. doi: 10.1126/science. 1090278

54. Nalls MA, Pankratz N, Lill CM, Do CB, Hernandez DG, Saad M, et al. Largescale meta-analysis of genome-wide association data identifies six new risk loci for Parkinson's disease. Nat Genet. (2014) 46:989-93. doi: 10.1038/ng.3043

55. Hou B, Zhang X, Liu Z, Wang J, Xie A. Association of rs356219 and rs3822086 polymorphisms with the risk of Parkinson's disease: a meta-analysis. Neurosci Lett. (2019) 709:134380. doi: 10.1016/j.neulet.2019.134380

56. Fernández-Santiago R, Martín-Flores N, Antonelli F, Cerquera C, Moreno $\mathrm{V}$, Bandres-Ciga $\mathrm{S}$, et al. SNCA and mTOR pathway single nucleotide polymorphisms interact to modulate the age at onset of Parkinson's disease. Mov Disord. (2019) 34:1333-44. doi: 10.1002/mds.27770

57. Ratner $\mathrm{MH}$, Fitzgerald E. Understanding of the role of manganese in parkinsonism and Parkinson disease. Neurology. (2017) 88:338-9. doi: 10.1212/WNL.0000000000003543

58. Langley MR, Ghaisas S, Ay M, Luo J, Palanisamy BN, Jin H, et al. Manganese exposure exacerbates progressive motor deficits and neurodegeneration in the MitoPark mouse model of Parkinson's disease: relevance to gene and environment interactions in metal neurotoxicity. Neurotoxicology. (2018) 64:240-55. doi: 10.1016/j.neuro.2017.06.002

59. Leyva-Illades D, Chen P, Zogzas CE, Hutchens S, Mercado JM, Swaim CD, et al. SLC30A10 is a cell surface-localized manganese efflux transporter, and parkinsonism-causing mutations block its intracellular trafficking and efflux activity. J Neurosci. (2014) 34:14079-95. doi: 10.1523/JNEUROSCI.2329-14.2014

60. Park JH, Hogrebe M, Grüneberg M, DuChesne I, von der Heiden AL, Reunert J, et al. SLC39A8 Deficiency: a disorder of manganese transport and glycosylation. Am J Hum Genet. (2015) 97:894-903. doi: 10.1016/j.ajhg.2015.11.003

61. Ng E, Lind PM, Lindgren C, Ingelsson E, Mahajan A, Morris A, et al. Genome-wide association study of toxic metals and trace elements reveals novel associations. Hum Mol Genet. (2015) 24:4739-45. doi: 10.1093/hmg/ ddv190

62. Carrera N, Arrojo M, Sanjuán J, Ramos-Ríos R, Paz E, Suárez-Rama JJ, et al. Association study of nonsynonymous single nucleotide polymorphisms in schizophrenia. Biol Psychiatry. (2012) 71:169-77. doi: 10.1016/j.biopsych.2011.09.032

63. Bruenig D, White MJ, Young RM, Voisey J. Subclinical psychotic experiences in healthy young adults: associations with stress and genetic predisposition. Genet Test Mol Biomarkers. (2014) 18:683-9. doi: 10.1089/gtmb. 2014.0111

64. Rothman KJ, Greenland S. Modern Epidemiology. 2nd ed. Philadelphia, PA: Lippincott Williams \& Wilkins (1998).

Conflict of Interest: The authors declare that the research was conducted in the absence of any commercial or financial relationships that could be construed as a potential conflict of interest.

Copyright (c) 2020 Lucchini, Guazzetti, Renzetti, Broberg, Caci, Covolo, Crippa, Gelatti, Hashim, Oppini, Pepe, Pilotto, Passeri, Placidi, Rizzetti, Turla, Wahlberg and Padovani. This is an open-access article distributed under the terms of the Creative Commons Attribution License (CC BY). The use, distribution or reproduction in other forums is permitted, provided the original author(s) and the copyright owner(s) are credited and that the original publication in this journal is cited, in accordance with accepted academic practice. No use, distribution or reproduction is permitted which does not comply with these terms. 